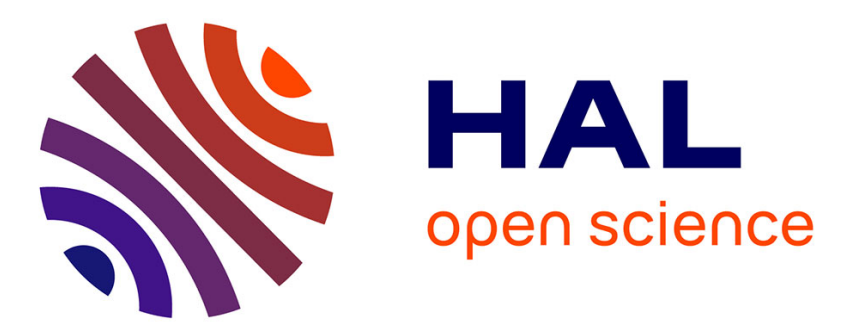

\title{
Design of a supervised flight control system for aircraft relative guidance
}

Thierry Miquel, Felix Mora-Camino, Jean-Marc Loscos, Karim Achaibou

\section{To cite this version:}

Thierry Miquel, Felix Mora-Camino, Jean-Marc Loscos, Karim Achaibou. Design of a supervised flight control system for aircraft relative guidance. DASC 2003, 22nd Digital Avionics Systems Conference, Oct 2003, Indianapolis, United States. pp 4.D.3 - 4.1-8, 10.1109/DASC.2003.1245845 . hal-00938057

\section{HAL Id: hal-00938057 \\ https://hal-enac.archives-ouvertes.fr/hal-00938057}

Submitted on 27 May 2014

HAL is a multi-disciplinary open access archive for the deposit and dissemination of scientific research documents, whether they are published or not. The documents may come from teaching and research institutions in France or abroad, or from public or private research centers.
L'archive ouverte pluridisciplinaire HAL, est destinée au dépôt et à la diffusion de documents scientifiques de niveau recherche, publiés ou non, émanant des établissements d'enseignement et de recherche français ou étrangers, des laboratoires publics ou privés. 


\title{
DESIGN OF A SUPERVISED FLIGHT CONTROL SYSTEM FOR AIRCRAFT RELATIVE GUIDANCE
}

\author{
Thierry Miquel, CENA and LAAS du CNRS, Toulouse, France \\ Félix Mora-Camino, LAAS du CNRS and ENAC, Toulouse, France \\ Jean-Marc Loscos, CENA, Toulouse, France \\ Karim Achaibou, LAAS du CNRS, Toulouse, France
}

\section{Introduction}

Considering the current and predicted levels of congestion of air traffic (see Figure 1), studies related to the delegation to the flight crew of some tasks currently performed by air traffic controllers are actively tackled today [1]. Among these studies, relative guidance between aircraft has appeared to be promising for the increase of air traffic capacity. The objective of this communication is to provide technical insight into the airborne devices and algorithms which may be used to automatically perform this new type of maneuver.

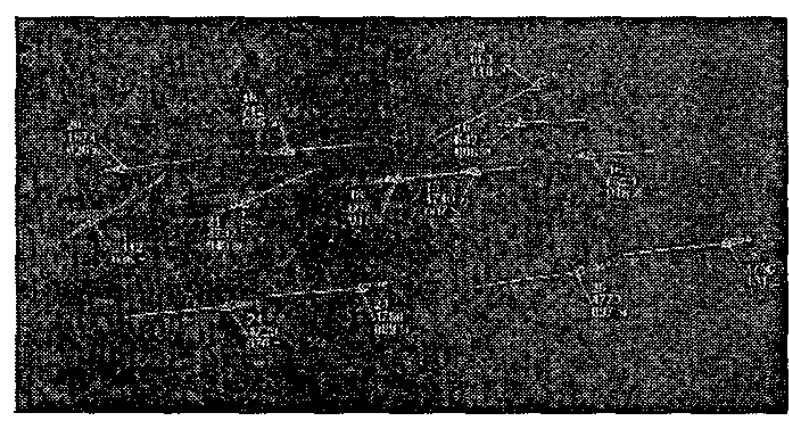

Figure 1. Radar Display at Paris-Charles de Gaulle

From an operational point of view, and assuming normal operations, the air traffic controller is relieved of providing instructions to the trailing aircraft for merging behind the leading aircraft and maintaining a given spacing once the flight crew has accepted a relative guidance clearance. Thus, the expected benefit of such new capabilities onboard aircraft is an increase of air traffic controller availability, which would result in increased air traffic capacity and/or safety. Enhancement of flight crew airborne traffic situational awareness is also expected with associated safety benefits. The feasibility of such a relative guidance device is based on the ability of each aircraft to broadcast and receive suitable navigation data thanks to Automatic Dependent Surveillance-Broadcast (ADS-B) [2]. Among those navigation data, identification, position, speed and heading are of interest for the design of the relative guidance control law.

The literature dealing with aircraft relative guidance for Unmanned Air Vehicles (UAV) or military aircraft is quite large: in [3] and [4], the control device was designed on a linearized model, whereas in [5] the proposed feedback linearizing control law exhibits a singularity when the desired relative position is zero which may result in infinitely large inputs.

Nevertheless, research for civil aircraft in the relative guidance field is still in its initial stage. Indeed, performances of such aircraft are more constrained than those of military aircraft or UAV. In addition, safety and passenger comfort are crucial. In [6] station keeping is performed manually by the flight deck, whereas in [7] the authors consider a proportional, integral, and derivative (PID) control to control longitudinal station keeping. In addition, very few papers concentrate on the automatic control of the merging maneuver before maintaining the desired position behind the leading aircraft. Indeed, the merging maneuver exhibits large nonlinearities which cannot be handled by linearization. In [8] an approach based on flatness synthesis has been presented where the separation objective is expressed in terms of distance rather than delay.

In this paper, the automation of the relative guidance is performed thanks to a recursive nonlinear control technique, namely backstepping [9]. This is a quite new design methodology for construction of both feedback control laws and associated Lyapunov functions in a systematic manner. In order to tackle safety and passenger 
comfort aspects, which are crucial points for commercial aircraft, the controller is supervised: the purpose of this device is to handle on-line the gain of the controller, taking into account the current value of the state in order to satisfy some limitations in commercial aircraft maneuvering capabilities.

The paper is organized as follows: in the preliminary section, reference frame and aircraft model are introduced. This leads to a nonlinear state space representation. The subsequent section presents the design of the controller. Then, the supervision device is presented. Simulation results are provided in order to illustrate the approach. Finally, conclusions are raised.

\section{Preliminaries}

\section{Separation Criteria}

The separation to be applied between aircraft can be expressed as a distance, which is the current practice by air traffic controllers, or as a delay. This paper investigates a constant time separation. The interest of such a criteria is that limiting constraints such as runway occupancy, wake vortex decay and human reactions are naturally expressed is terms of time [10]. On the other hand, as current civil aviation regulations set distance separation standard between aircraft, the time delay separation objective must be chosen so that the minimum distance separation standard is not violated.

\section{Aircraft Dynamics}

As introduced in [3], it is assumed that the trailing aircraft is equipped with two autopilots which are able to operate in a decoupled fashion:

- Heading is assumed to be controlled through coordinated turns while roll and bank angle dynamics are neglected. Thus, the (small) bank angle change command, denoted $\varphi_{c}$, is related to the yaw rate $\dot{\psi}$ through the following relation, where $g$ is the acceleration of gravity and $V$ the actual airspeed :

$$
\dot{\psi}=\frac{g}{V} \operatorname{tg}\left(\varphi_{c}\right) \approx \frac{g}{V} \varphi_{c}
$$

- Airspeed is assumed to be controlled by auto throttle without affecting the aircraft's altitude through a first order linear model. Thus, the longitudinal acceleration $\dot{V}$ is related to the commanded airspeed $V_{c}$, the current airspeed $V$ and a time constant $\tau_{V}$ through the following relation :

$$
\dot{V}=\frac{V_{c}-V}{\tau_{V}}
$$

\section{Kinematics of Relative Motion}

This paper focuses on the simplified case where the aircraft relative motion is limited within the horizontal plane with no wind.

The nomenclature is indicated in the Figure 2.

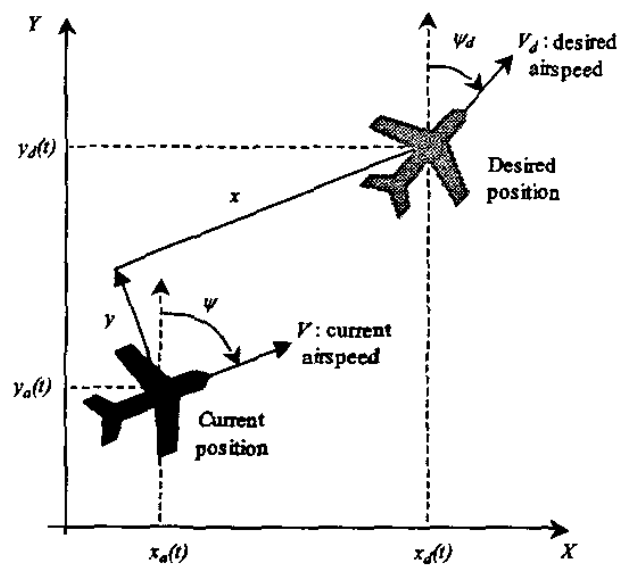

Figure 2. Nomenclature

- $x_{a}(t), y_{a}(t)$ : the actual (or current) position of the trailing aircraft,

- $x_{d}(t), y_{d}(t)$ : the desired position for the trailing aircraft. In the context of constant time separation, the desired position is the position of the leading aircraft ninety or so seconds before the current time,

- $\quad V, V_{d}$ : respectively, the current and the desired airspeed,

- $\psi, \psi_{d}:$ respectively, the current and the desired heading,

- $x, y$ : respectively, the along-track distance and the cross-track distance between the actual and the desired position, expressed in the reference frame affixed to the current position. 
With the notation shown in the previous figure, the equations of relative motion between the actual and desired positions are found to be:

$$
\left[\begin{array}{c}
\dot{x} \\
\dot{y}
\end{array}\right]=\left[\begin{array}{cc}
0 & \dot{\psi} \\
-\dot{\psi} & 0
\end{array}\right]\left[\begin{array}{l}
x \\
y
\end{array}\right]+\left[\begin{array}{c}
-V+V_{d} \cos \left(\psi-\psi_{d}\right) \\
-V_{d} \sin \left(\psi-\psi_{d}\right)
\end{array}\right]
$$

\section{Controller Design}

Backstepping is a quite new recursive design methodology for construction of both feedback control laws and associated Lyapunov functions. It was introduced by Krstic, Kanellakopoulos and Kokotovic [9]. Backstepping applies on cascaded nonlinear systems and, contrary to feedback linearization, it allows to retain stabilizing nonlinearities in the control design. This paper considers a vectorial backstepping technique which exploits a skew-symmetric property of a matrix which appears in the relative motion kinematics.

The state space representation of the system is obtained by gathering (1), (2) and (3):

$$
\begin{gathered}
\underline{\dot{x}}_{1}=a\left(\underline{x}_{2}, \underline{u}_{)} \underline{x}_{1}+b\left(\underline{x}_{2}\right)\right. \\
\underline{x}_{2}=c\left(\underline{x}_{2}\right)+d\left(\underline{x}_{2}\right) \underline{u}
\end{gathered}
$$

Where:

$$
\left\{\begin{array}{l}
\underline{x}_{1}=\left[\begin{array}{ll}
x & y
\end{array}\right]^{T} \\
\underline{x}_{2}=\left[\begin{array}{ll}
\psi & V
\end{array}\right]^{T} \\
\underline{u}=\left[\begin{array}{ll}
\varphi_{c} & V_{c}
\end{array}\right]^{T}
\end{array}\right.
$$

And:

$$
\left\{\begin{array}{l}
a\left(\underline{x}_{2}, \underline{u}\right)=\left[\begin{array}{cc}
0 & g \varphi_{c} / V \\
-g \varphi_{c} / V & 0
\end{array}\right] \\
b\left(\underline{x}_{2}\right)=\left[\begin{array}{c}
-V+V_{d} \cos \left(\psi-\psi_{d}\right) \\
-V_{d} \sin \left(\psi-\psi_{d}\right)
\end{array}\right] \\
c\left(\underline{x}_{2}\right)=\left[\begin{array}{c}
0 \\
-V / \tau_{\nu}
\end{array}\right] \\
d\left(\underline{x}_{2}\right)=\left[\begin{array}{cc}
g / V & 0 \\
0 & 1 / \tau_{V}
\end{array}\right]
\end{array}\right.
$$

The design objective is to render the equilibrium point $\left(\underline{x}_{1}=\underline{0} ; \underline{x}_{2}=\underline{x}_{2}\right)$ globally asymptotically stable. Since the nonlinear systems (4) and (5) consist of two states $\underline{x}_{l}$ and $\underline{x}_{2}$, and taking into account the fact that the matrix $a\left(\underline{x_{2}}, \underline{u}\right)$ which appears in (4) is skew-symmetric, the vectorial backstepping technique can be applied by considering systems (4) and (5) as two cascaded systems:

- system (4) has $b\left(\underline{x}_{2}\right)$ as virtual input, and $\underline{x}_{I}$ as output,

- system (5) has $\underline{u}$ as input, and $\underline{x}_{2}$ as output. For system (4), the virtual control $b\left(\underline{x}_{2}\right)$ is chosen in order to stabilize it around $\underline{x}_{l}=\underline{0}$; by denoting $\Lambda_{I}$ a positive definite matrix (tuning parameter) and by $z$ a stabilizing function which provides feedback to the system, the virtual control is chosen as follows:

$$
b\left(\underline{x}_{2}\right)=\underline{z}-\Lambda_{1} \underline{x}_{1}
$$

In a second step, let us consider the following candidate Lyapunov function, where $k_{l}$ is a positive number (tuning parameter):

$$
V=\frac{k_{1}}{2} \underline{x}_{1}^{T} \underline{x}_{1}+\frac{1}{2} \underline{z}^{T} \underline{z}
$$

Taking into account (8) and the skewsymmetric property of the matrix $a\left(\underline{x}_{2}, \underline{u}\right)$, the time derivative of (9) leads to :

$\dot{V}=-k_{1} \underline{x}_{1}^{T} \Lambda_{1} \underline{x}_{1}+\underline{z}^{T}\left(k_{1} \underline{x}_{1}+\Lambda_{1} \underline{\dot{x}}_{1}+\nabla b\left(\underline{x}_{2}\right) \underline{\dot{x}}_{2}\right)$ by:

Where $\square b\left(\underline{x}_{2}\right)$ is the Jacobian matrix defined

$$
\nabla b\left(\underline{x}_{2}\right) \hat{=} \frac{\partial b\left(\underline{x}_{2}\right)}{\partial \underline{x}_{2}^{T}}
$$

Finally, the control vector $\underline{u}$ is chosen by expanding $\underline{\dot{x}}_{2}$ in (10) thanks to (5) so that the time derivative of the candidate Lyapunov function is negative. By denoting $\Lambda_{2}$ a positive 
definite matrix (tuning parameter), this leads to the following:

$$
\begin{array}{r}
\underline{u}=\left(\nabla b\left(\underline{x}_{2}\right) d\left(\underline{x}_{2}\right)\right)^{-1}\left(-k_{1} \underline{x}_{1}-\Lambda_{1} \underline{\dot{x}}_{1}\right. \\
\left.-\nabla b\left(\underline{x}_{2}\right) c\left(\underline{x}_{2}\right)-\Lambda_{2} \underline{z}\right)
\end{array}
$$

To be more specific, let us select $A_{1}$ and $\Lambda_{2}$ as diagonal matrix:

$$
\left\{\begin{array}{l}
\Lambda_{1}=\operatorname{diag}\left(\lambda_{x}, \lambda_{y}\right) \\
\Lambda_{2}=\operatorname{diag}\left(\lambda_{v}, \lambda_{\psi}\right)
\end{array}\right.
$$

Thus, control law (12) expands as follows:

$$
\left\{\begin{array}{r}
\varphi_{c}=\frac{V}{g\left(V_{d} \cos \left(\psi-\psi_{d}\right)+\lambda_{y} x\right)}\left\{\left(k_{1}+\lambda_{y} \lambda_{\psi}\right) y\right. \\
\left.-\left(\lambda_{y}+\lambda_{\psi}\right) V_{d} \sin \left(\psi-\psi_{d}\right)\right\} \\
V_{c}=V+\tau_{V}\left\{\left(\lambda_{x}+\lambda_{V}\right)\left(V_{d} \cos \left(\psi-\psi_{d}\right)-V\right)\right. \\
+\left(k_{1}+\lambda_{x} \lambda_{V}\right) x \\
\left.+\frac{g}{V} \varphi_{c}\left(\lambda_{x} y-V_{d} \sin \left(\psi-\psi_{d}\right)\right)\right\}
\end{array}\right.
$$

\section{Supervision of the Controller}

The purpose of the controller supervisor is to handle on-line the gain of the controller, taking into account the current value of the state in order to comply with some limitations in commercial aircraft maneuvering capabilities. This is illustrated in the Figure 3.

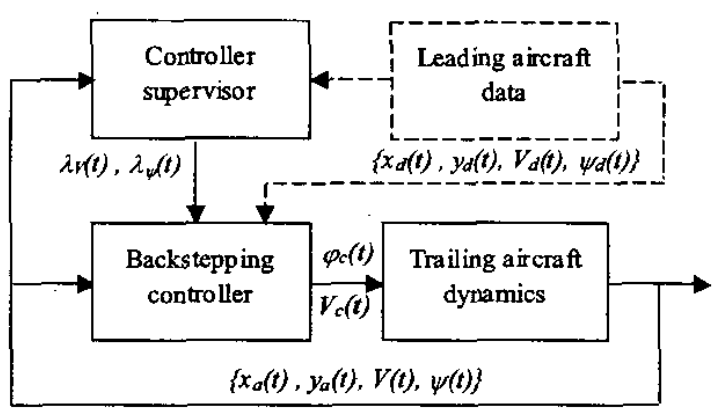

Figure 3. Supervised Controller

To be more specific, this paper focuses on the following constraints:

- to give favor to constant speed maneuver when the cross-track distance between the trailing and the leading aircraft is 'high'. The idea behind this constraint is to do 'one thing at a time' in order to enable the flight crew to understand the controller behavior. As a consequence, the merging maneuver should start at constant airspeed as far as the leading aircraft is not in the line of sight of the trailing aircraft. Then, when the trailing aircraft is established behind the leading aircraft, airspeed may vary,

- to provide accelerations which are acceptable from a passenger point of view,

- to maintain bank angle lower than the maximum bank angle of operation,

- to maintain the airspeed of the trailing aircraft between minimum and maximum speed of operation.

In order to satisfy the preceding constraints, the tuning parameters $k_{J}, \Lambda_{I}$ and $A_{2}$ shall be set dynamically. First of all, it is worth noticing that $k_{I}$ and $A_{1}$ have been assumed to be constant during the design process, whereas $\Lambda_{2}=\operatorname{diag}\left(\lambda_{V}, \lambda_{\psi}\right)$ may depend on time. In addition, expression (14) shows that parameter $\lambda_{V}$ just appears within the expression of the commanded speed $V_{c}$, whereas parameter $\lambda_{\psi}$ just appears within the expression of the commanded bank angle $\varphi_{c}$. Thus, the idea is to set $\lambda_{V}$ and $\lambda_{\psi}$ so that it compensates exactly for $k_{1}$ and $\Lambda_{L}$ in order to reduce the number of parameters to be tuned. To achieve this goal, let us select $\lambda_{V}(t)$ and $\lambda_{y}(t)$ as follows: 


$$
\left\{\begin{array}{r}
\lambda_{V}(t)=\lambda_{V_{0}}(t)-\frac{1}{V_{d} \cos \left(\psi-\psi_{d}\right)-V+\lambda_{x} x}\left(k_{1} x\right. \\
+\lambda_{x}\left(V_{d} \cos \left(\psi-\psi_{d}\right)-V\right) \\
\left.+\frac{g}{V} \varphi_{c}\left(\lambda_{x} y-V_{d} \sin \left(\psi-\psi_{d}\right)\right)\right) \\
\lambda_{\psi}(t)=\lambda_{\psi_{0}}(t)-\frac{1}{\lambda_{y} y-V_{d} \sin \left(\psi-\psi_{d}\right)}\left(k_{1} y\right. \\
\left.-\lambda_{y} V_{d} \sin \left(\psi-\psi_{d}\right)\right)
\end{array}\right.
$$

Introducing those values for $\lambda_{Y}(t)$ and $\lambda_{\psi}(t)$ into (14) leads to the following expressions for the commanded bank angle and airspeed where parameter $k_{l}$ has disappeared:

$$
\left\{\begin{array}{l}
\varphi_{c}=\frac{V\left(\lambda_{y} y-V_{d} \sin \left(\psi-\psi_{d}\right)\right)}{g\left(V_{d} \cos \left(\psi-\psi_{d}\right)+\lambda_{y} x\right)} \lambda_{\psi_{0}}(t) \\
\frac{V_{c}-V}{\tau_{V}}=\left(V_{d} \cos \left(\psi-\psi_{d}\right)-V+\lambda_{x} x\right) \lambda_{v_{0}}(t)
\end{array}\right.
$$

To give preference to maneuver with no longitudinal acceleration when the cross-track distance $y(t)$ is 'high', $\lambda_{v o}(t)$ is set as follows:

$$
\lambda_{V_{0}}(t)=\lambda_{V_{0}}(0) \exp \left(-\alpha_{0} \mid y(t)\right)
$$

The constraint dealing with bank angle will be treated through parameter $\lambda_{y}$. As a consequence, $\lambda_{\varphi_{0}}(t)$ is set as a constant:

$$
\lambda_{\psi_{0}}(t)=\lambda_{\psi_{0}}(0)
$$

In the following, we denote :

- $V_{\min }$ the minimum speed of operation,

- $V_{\max }$ the maximum speed of operation,

- $a_{\text {max }}$ the maximum acceleration acceptable from a passenger point of view,

- $\varphi_{c \max }$ the maximum bank angle of operation.

In order to satisfy the acceleration and the bank angle constraints, it is clear from relations (16) that parameters $\lambda_{x}$ and $\lambda_{y}$ shall be chosen as a function of $\lambda_{\psi 0}$ and $\lambda_{V \theta}$ as follows:

$$
\left\{\begin{array}{l}
0<\lambda_{y} \leq \frac{1}{y_{\max }}\left(g \frac{V_{d_{\min }}}{V_{\max }} \frac{\varphi_{c_{\max }}}{\lambda_{\psi_{0}}(0)}-V_{d_{\max }}\right) \\
0<\lambda_{x} \leq \frac{1}{x_{\max }}\left(\frac{a_{\max }}{\lambda_{V_{0}}(0)}-\left(V_{d_{\max }}+V_{\max }\right)\right)
\end{array}\right.
$$

Finally, the airspeed of the trailing aircraft is maintained between the minimum and maximum speed of operation by limiting the outputs of the controller.

\section{Simulations}

\section{Scenario}

In this section, a scenario is designed in order to evaluate the properties of the control laws previously designed. A special attention is given on the behavior of such a controller to the changes of heading and airspeed from the leading aircraft.

The leading aircraft starts at $\mathrm{x}_{0}=0 \mathrm{NM}, \mathrm{y}_{0}=0$ $\mathrm{NM}$, with initial conventional airspeed and heading of $200 \mathrm{kts}$ and 90 degrees respectively. It is supposed to broadcast position, airspeed and heading every second. No wind is assumed.

The controlled bank angle of the leading aircraft is always zero, except between $220 \mathrm{sec}$ and $310 \mathrm{sec}$ where the leader changes its heading of about 155 degrees with a bank angle of 20 degrees.

The controlled conventional airspeed of the leading aircraft is first set at $220 \mathrm{kts}$ for $\mathrm{t} \leq 400 \mathrm{sec}$, and then is set to $160 \mathrm{kts}$.

The trailing aircraft starts at $\mathrm{x}_{0}=-8 \mathrm{NM}, \mathrm{y}_{0}=$ $+4 \mathrm{NM}$, with initial conventional airspeed and heading of $220 \mathrm{kts}$ and 90 degrees respectively.

The simulation lasts $15 \mathrm{~min}(900 \mathrm{sec})$, and the requested time based separation for the trailing aircraft is constant and equal to $90 \mathrm{sec}$ behind the leading aircraft. 
During the maneuver, the outputs (i.e. the controlled bank angle and airspeed) of the relative guidance controller are limited to the following 'safe' values:

$$
\left\{\begin{array}{l}
-20 \mathrm{deg} . \leq \varphi_{c} \leq+20 \mathrm{deg} \\
140 k t s \leq V_{c} \leq 250 k t s
\end{array}\right.
$$

The time constants $\tau_{V}$ and $\tau_{\varphi}$ of the airspeed and heading autopilots are set to the following values:

$$
\left\{\begin{array}{l}
\tau_{V}=40 \mathrm{sec} \\
\tau_{\varphi}=5 \mathrm{sec}
\end{array}\right.
$$

The values of the gains for the controller and the supervisor have been set as follows:

$$
\left\{\begin{array}{l}
\lambda_{V_{0}}(0)=1 \mathrm{sec}^{-1} \\
\alpha_{0}=5 N M^{-1} \\
\lambda_{\psi_{0}}(0)=0.5 \mathrm{sec}^{-1} \\
\lambda_{x}=0.01 \mathrm{sec}^{-1} \\
\lambda_{y}=0.01 \mathrm{sec}^{-1}
\end{array}\right.
$$

\section{Movement in the Horizontal Plane}

The movements of the leading and trailing aircraft in the horizontal plane are shown in the following figure. As expected, the trailing aircraft move towards the leading aircraft (See Figure 4).

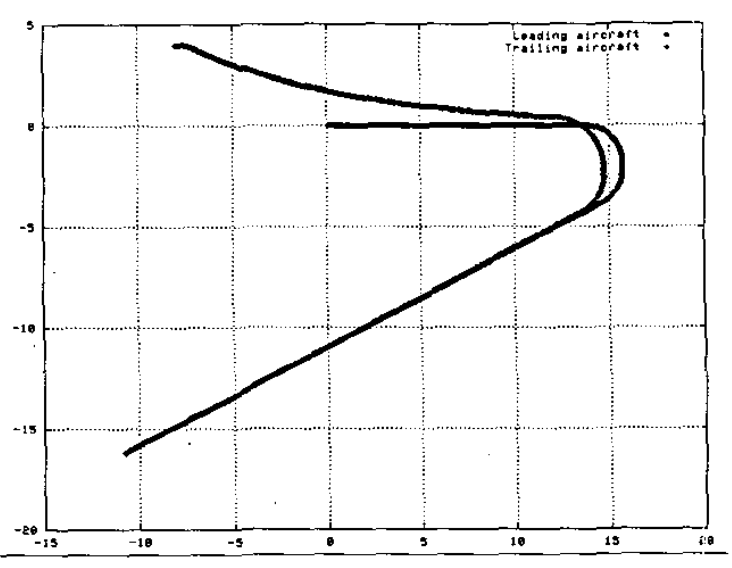

Figure 4. Movement of the Trailing and Leading Aircraft in the Horizontal Plane (Axes in NM)

\section{Range}

The evolution of the actual range between the leading and the trailing aircraft is shown in the following figure. Before leading aircraft speed change, the desired slant range is $5.5 \mathrm{NM}$, i.e. 220 $k t s \times 90 \mathrm{sec}$. Due the heading change of the leading aircraft between $220 \mathrm{sec}$ and $310 \mathrm{sec}$, the value of the slant range decreases to about 4.5 NM before starting to increase: Finally, when the leading aircraft is established on the final straight line at constant speed, the slant range reduces as intended to 4 NM, i.e. $160 \mathrm{kts} \times 90 \mathrm{sec}$ (See Figure 5).

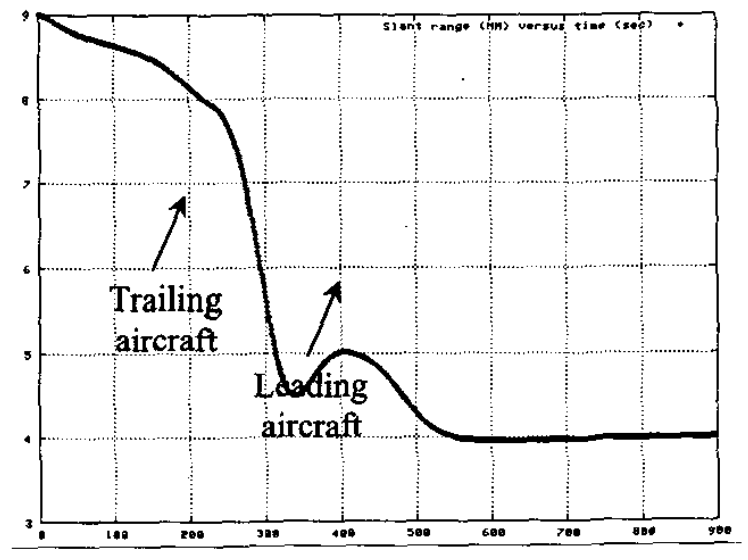

Figure 5. Slant Range (NM) between the Leading and the Trailing Aircraft versus Time (Sec) 


\section{Airspeed}

The evolution of the actual airspeeds of the leading and the trailing aircraft is shown in the following figure. As designed, the airspeed is constant, $220 \mathrm{kts}$, when the cross-track distance between the trailing and the leading aircraft is 'high'. At about 2 NM of cross-track distance, the airspeed starts to increase up to the maximum operation airspeed, i.e. $250 \mathrm{kts}$. The change in heading for the leading aircraft induces the decrease to about $205 \mathrm{kts}$ before a small increase. Finally, the decrease towards $160 \mathrm{kts}$ of the airspeed of the leading aircraft induces the decrease of the airspeed of the trailing aircraft towards the same value (see Figure 6).

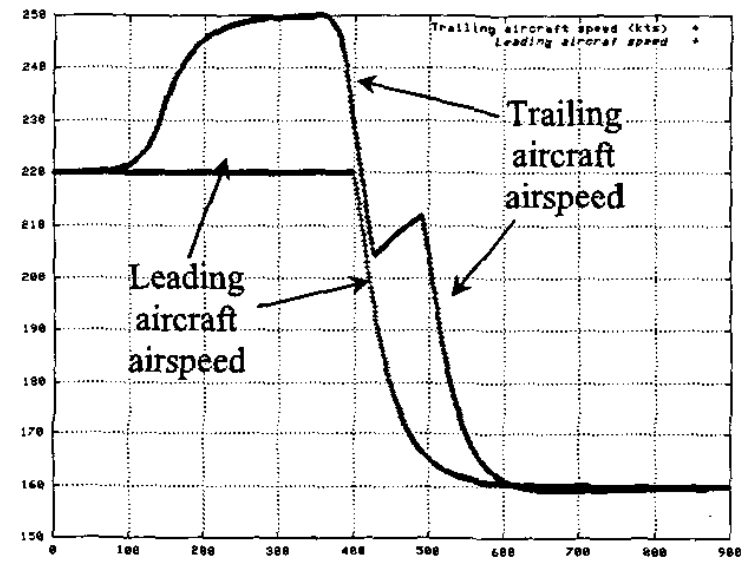

Figure 6. Leading and Trailing Aircraft Airspeed (Kts) versus Time (Sec)

\section{Bank Angle}

The evolution of the controlled bank angle of the trailing aircraft is shown in the Figure 7 . The choice of the value of $\lambda_{y 0}(0)$ allows for clean turns thanks to a rapid command of the maximum / minimum values of the bank angle, i.e. 20 degrees.

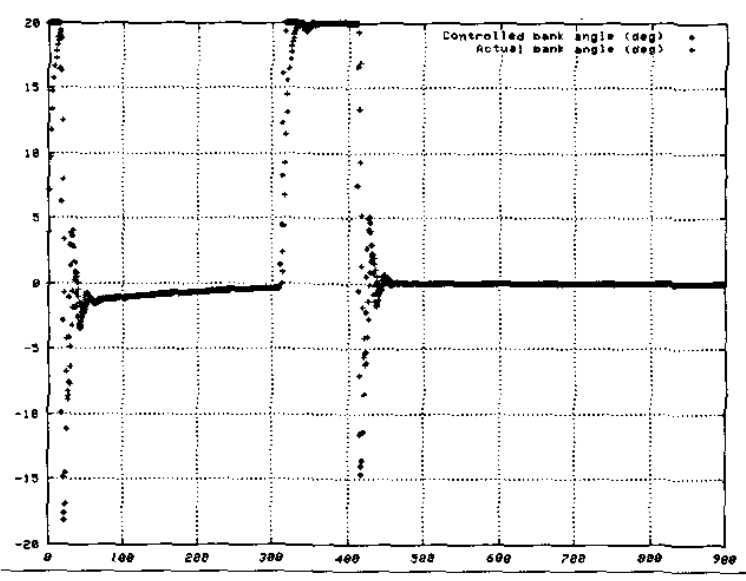

Figure 7. Controlled Bank Angle (Degrees) versus Time (Sec)

\section{Load Factor}

Finally, the evolution of the load factor for the trailing aircraft is shown in the Figure 8. It shows that the maneuver remains quite comfortable for the passengers. Indeed, maximum longitudinal acceleration for civil flights is $2 f p s^{2}$, i.e. $1.06 \times g$ [11].

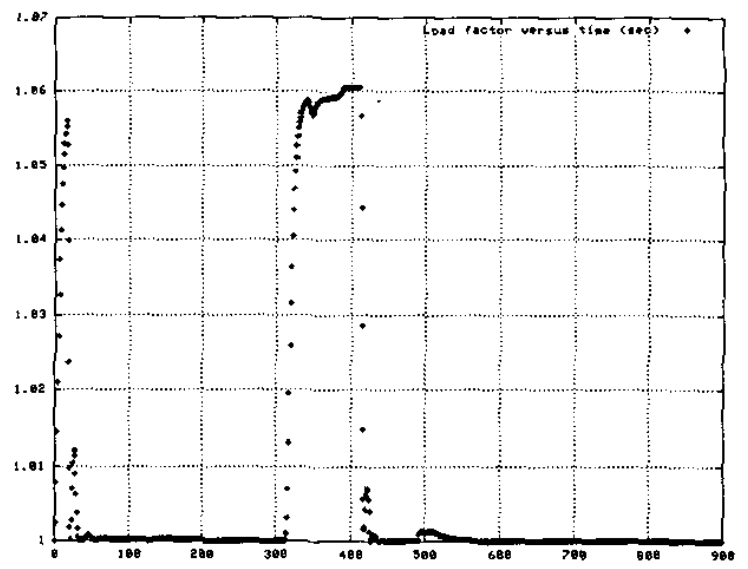

Figure 8. Load Factor versus Time (Sec)

\section{Conclusion}

In this paper, the design of a supervised controller to move towards a leading aircraft and to maintain a constant time delay behind it has been considered. A simplified case where the aircraft relative motion is limited within the horizontal plane without wind has been considered. 
The proposed approach is based on backstepping. One of the key-point of such a design is the use of a skew-symmetric property of a matrix which appears in the relative motion kinematics. Furthermore, the supervisor has been designed in order to give favor to constant speed maneuver when the cross-track distance between the trailing and the leading aircraft is 'high'.

As far as available on-line information and communications are concerned, more realistic performances may be achieved by introducing wind and noisy data filtered by an observer.

This approach appears quite interesting. It requires further studies, especially on the robustness of such a controller to noisy data from the leading aircraft and to wind gusts.

\section{References}

[1] European commission \& Eurocontrol, CARA/ASAS Activity 5 description of a first package of GS/AS applications, version 2.2, september 2002

[2] Ivanescu D., Hoffman E., Zeghal K., Impact of ADS-B link characteristics on the performances of in-trail following aircraft, AIAA Guidance, Navigation and Control Conference, Monterey, USA, August 2002

[3] Pachter M., D'Azzo J.J., Dargan J.L., Automatic formation flight control, Journal of guidance, control and dynamics, vol. 17, pp 13801383,1994
[4] Giulietti F., Pollini L., Innocenti M., Autonomous Formation Flight, IEEE Control Systems Magazine, December 2000

[5] Li S.M., Boskovic J.D., Mehra R.K., Globally stable automatic formation flight control in two dimensions, AIAA Guidance, Navigation and Control Conference. Montreal, August 2001, Paper: No. 2001-4046

[6] Agelii M., Olausson C., Flight deck simulations of station keeping, ATM 2001 R\&D seminar, Santa Fe, paper no. 17

[7] Vanken P., Hoffman E., Zeghal K., Influence of speed and altitude profile on the dynamics of intrail following aircraft, AIAA-2000-4362

[8] Miquel T., Mora-Camino F., Levine J., Aircraft relative guidance: a flatness synthesis of a new autopilot mode, $5^{\text {th }}$ USA/Europe Air Traffic Management R\&D Seminar, Budapest, Hungary, June 2003

[9] Krstic M., Kanellakopoulos I., Kokotovic P.V., Nonlinear and Adaptative Control Design, John Wiley \& Sons Ltd, New York, 1995

[10] Hoffman E., Ivanescu D., Shaw C., Zeghal K., Analysis of constant time delay airborne spacing between aircraft of mixed types in varying wind conditions, $5^{\text {th }}$ USA/Europe Air Traffic

Management R\&D Seminar, Budapest, Hungary, June 2003

[11] Eurocontrol Experimental Center, User manual for the base of aircraft data (BADA), version 3.3, December 2000 